\title{
A peculiar bilateral adrenal tumor: A case of asymptomatic left adrenal myelolipoma with right adrenal adenoma
}

\author{
Chidi Okoroafor, Catherine Obadina, Cornelius Njoku, \\ Okechukwu Mgbemena
}

\begin{abstract}
Adrenal incidentalomas (AI) are increasingly common due to modern use of several imaging modalities. Adrenal adenomas comprise $75 \%$ of all adrenal incidentalomas while adrenal myelolipomas (AML) are the second most common. Several studies report different incidence rates for AML ranging from $2.6 \%$ to $6 \%$. Other differentials for adrenal tumors include: pheochromocytoma, adrenocortical carcinoma, metastatic cancer, hematomas, hormone-producing tumors and adrenal hyperplasia. On this case report, we discuss a patient with bilateral adrenal tumors - a right adrenal adenoma and a left myelolipoma. We discuss the embryology, pathophysiology, histology, and clinical importance of myelolipoma to create awareness in the medical community. The clinical awareness of myelolipoma may help to decrease cost of care by decreasing the need for unnecessary medical procedures and repeat imaging.
\end{abstract}

Keywords: Adrenal mass, Adrenal tumor, Incidentaloma, Myelolipoma

Chidi Okoroafor ${ }^{1}$, Catherine Obadina ${ }^{2}$, Cornelius Njoku ${ }^{1}$, Okechukwu Mgbemena ${ }^{3}$

Affiliations: ${ }^{1}$ Imo State University, Owerri, Nigeria; ${ }^{2}$ Emory University, Atlanta, GA, USA; ${ }^{3}$ Department of Hospital Medicine, Cypress Fair Banks Medical Center, Houston TX, USA.

Corresponding Author: Okechukwu Mgbemena, Department of Hospital Medicine, Cypress Fair Banks Medical Center, 10655 Steepletop Dr, Houston, TX 77065, USA; Email: omgbeme@gmail.com

Received: 28 June 2018

Accepted: 27 July 2018

Published: 20 August 2018

\section{How to cite this article}

Okoroafor C, Obadina C, Njoku C, Mgbemena O. A peculiar bilateral adrenal tumor: A case of asymptomatic left adrenal myelolipoma with right adrenal adenoma. Int $\mathrm{J}$ Case Rep Images 2018;9:100944Zo1CO2018.

Article ID: 100944Zo1CO2018

$* * * * * * * * *$

doi: 10.5348/100944Zo1CO2018CR

\section{INTRODUCTION}

Adrenal Incidentalomas (AI) are asymptomatic adrenal tumors noted on imaging such as Computed Tomography (CT) and Magnetic Resonance Imaging (MRI). Most of these tumors are discovered during patient evaluation for unrelated symptoms [1]. Adrenal adenomas remain the most common cause of AI, comprising $75 \%$ of all AI [1]. Other differentials for AI include Pheochromocytoma (5\%); Primary Aldosteronism (1\%); and Myelolipomas (2.6-6\%) [2]. Malignancy is a major concern with AIs. Of 2005 patients with AI evaluated by Young, et. al, 80\% had benign tumors; $4.7 \%$ were malignant; and $2.5 \%$ were metastatic at time of evaluation [3].

Adrenal myelolipomas are benign adrenal tumors composed of extramedullary hematopoietic elements interspersed within adipose tissue [4]. The natural history of AML is not completely understood and its embryologic origin remains unclear due to its rarity [5-7]. AML vary in size; from a few millimeters to over 30 centimeters and are mostly unilateral [5-7]. Although most myelolipomas are asymptomatic, a few percentages can cause symptoms in some patients due to mass effect. Symptoms in those cases include palpable flank mass and pain, hematuria, secondary hypertension and retroperitoneal hemorrhage [6-7]. 


\section{EDORIUM Journals}

Int J Case Rep Images 2018;9:100944Z01CO2018.

www.ijcasereportsandimages.com

\section{CASE REPORT}

Our patient is a 65-year-old male with previous history of CSF leak status post repair, Hypertension and Diabetes who presented with upper respiratory symptoms including cough and nasal congestion. Our patient had stable vital signs and his initial lab values were unremarkable. Chest X-ray was significant for illdefined infiltrate and follow up chest CT had interstitial infiltrate consistent with pneumonia and incidental bilateral adrenal tumors. Dedicated CT of abdomen and pelvis confirmed presence of bilateral adrenal tumors. The right adrenal tumor measured $0.9 \times 1 \times 1 \mathrm{~cm}$, with 7 Hounsfield units (HU) consistent with adenoma. The left adrenal gland had a tumor size of $1.9 \times 1.7 \times 1.9 \mathrm{~cm}$ with 48 pre-contrast HU suspicious for malignancy (Figure 1). Patient was unable to undergo adrenal MRI due to history of bullet fragments lodged in his thoracic spine.

Patient had a CT-guided biopsy for further evaluation. The histopathology of the left adrenal specimen was significant for sheets of hematopoietic cells including megakaryocytes, admixed with few mature adipocytes consistent with left adrenal myelolipoma (Figure 2). Our patient did not pursue biopsy of the right adrenal tumor because based on radiographic characteristics noted earlier, it was likely to be an adenoma. Screening lab values for functioning adrenal tumor including serum cortisol, catecholamines, metanephrines, normetanephrines and renin/aldosterone were within normal limits suggestive of non-functional adrenal tumors. Patient had no complications from the biopsy and was discharged from the hospital at postoperative day 2.

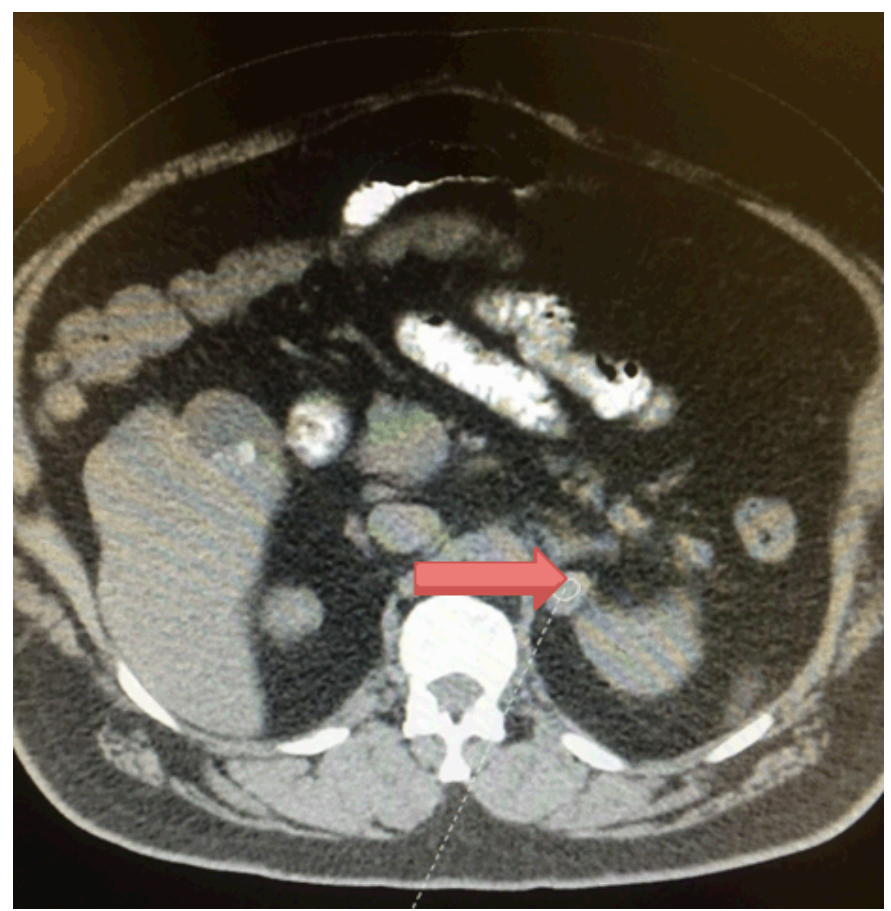

Figure 1: Abdominal CT scan showing left sided adrenal tumor measuring $1.9 \times 1.7 \times 1.9 \mathrm{~cm}$. Pre-contrast Hounsfield unit of 48 suspicious for malignancy.

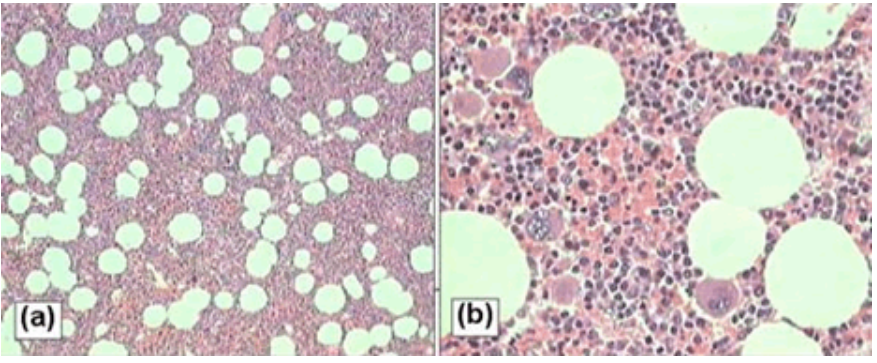

Figure 2: Histopathologic tissue containing all three hematopoietic cell lines admixed with mature adipocytes consistent with adrenal myelolipoma. (a) Low power micrograph (H\&E x50); (b) High power micrograph (H\&E x400).

\section{DISCUSSION}

Adrenal Myelolipoma (AML) is a rare benign nonfunctional neoplasm that consists of adipocytes and mature hematopoietic cells [7]. AML was first described by Gierke in 1905 as a mass of fat tissue mixed with myeloid and erythroid tissue [8]. The incidence of AML increases with age with most cases reported in the $5^{\text {th }}$ and 6th decades of life [1]. AML remains an important differential for an adrenal incidentaloma (AI) constituting about $2-6 \%$ of all incidentalomas while adrenal adenomas and pheochromocytoma make up the majority, $75 \%$ and $5 \%$ of AI respectively [2]. An embryological origin of AML remains unclear and evolving. Among varying hypotheses, the most widely accepted hypothesis suggests AML originates from metaplasia of reticuloendothelial cells of blood capillaries [1]. AMLs are more common on the right than left and have been found to be bilateral in only $12 \%$ of cases [7]. AMLs are usually asymptomatic but in rare instances, they can present with symptoms such as flank pain and abdominal discomfort. AMLs can vary in size from few millimeters up to large tumors greater than $10 \mathrm{~cm}$ in size, capable of producing symptoms due to mass effect on surrounding tissues or due to rupture and hemorrhage [9]. On CT, AMLs are usually well-circumscribed fat-containing adrenal mass with low attenuation values of -20 to $-30 \mathrm{HU}$ which can be differentiated from adenomas. Adenomas are usually smaller in size with attenuation values of -10 to $-30 \mathrm{HU}$ and up to $50 \%$ IV contrast washout in delayed studies [10].

Our case describes a patient with bilateral tumor a right adrenal adenoma and a left AML. The left AML had a pre-contrast CT HU of 48 with $87 \%$ absolute washout which was suspicious for malignancy [10-11] despite being non calcified or hemorrhagic. Pathology of specimen obtained through CT guided biopsy was consistent with AML. Tumors were also non-functioning as hormonal studies were within normal range.

Our case shows a unique presentation of an adrenal adenoma in concomitant occurrence with a myelolipoma, a combination that is rare.

A few reports have discussed AML coexisting with a non-functioning adrenal adenoma in the same adrenal 


\section{EDORIUM Journals}

gland [12-13] but to our knowledge none have discussed any case with bilateral AI - an AML and Adenoma coexisting separately and concomitantly.

\section{CONCLUSION}

AMLs are rare non-functional and mostly asymptomatic benign $\mathrm{AI}$, which can vary in size from small tumors to relatively large masses. AMLs are often found incidentally on CT with characteristic high fat content and low attenuation values of -20 to -30 HU. Embryologic origin of AMLs remains unclear. For asymptomatic AMLs, total surgical excision or repeat imaging is typically not needed except in cases where symptoms develop due to mass effect, rupture or hemorrhage of the AML.

\section{REFERENCES}

1. Song JH, Chaudhry FS, Mayo-Smith WW. The incidental adrenal mass on CT: Prevalence of adrenal disease in 1,049 consecutive adrenal masses in patients with no known malignancy. AJR Am J Roentgenol 2008 May;190(5):1163-8.

2. Lam KY, Lo CY. Adrenal lipomatous tumours: A 30 year clinicopathological experience at a single institution. J Clin Pathol 2001 Sep;54(9):707-12.

3. Young WF Jr. Management approaches to adrenal incidentalomas. A view from Rochester, Minnesota. Endocrinol Metab Clin North Am 2000 Mar;29(1):159-85, x.

4. Ramirez M, Misra S. Adrenal myelolipoma: To operate or not? A case report and review of the literature. Int J Surg Case Rep 2014;5(8):494-6.

5. Olsson CA, Krane RJ, Klugo RC, Selikowitz SM. Adrenal myelolipoma. Surgery 1973 May;73(5):66570 .

6. Han M, Burnett AL, Fishman EK, Marshall FF. The natural history and treatment of adrenal myelolipoma. J Urol 1997 Apr;157(4):1213-6.

7. Posses SP, Prado BC, Bechara GR, Puppim AR, Carli CRS, Miranda MML. Giant bilateral adrenal myelolipoma: Case presentation and a brief literature review. Urol Case Rep 2018 Mar 15;18:67-9.

8. Gierke E. Uber Knochenmarks gwebe in der nebenniere. Zeigler's beitrage. J Path Anat 1905;7:311-24.

9. Al-Bahri S, Tariq A, Lowentritt B, Nasrallah DV. Giant bilateral adrenal myelolipoma with congenital adrenal hyperplasia. Case Rep Surg 2014;2014:728198.

10. Shenoy VG, Thota A, Shankar R, Desai MG. Adrenal myelolipoma: Controversies in its management. Indian J Urol 2015 Apr-Jun;31(2):94-101.

11. Francis IR. Distinguishing benign from malignant adrenal masses. Cancer Imaging 2003;3(2):102-10

12. Yip L, Tublin ME, Falcone JA, et al. The adrenal mass: Correlation of histopathology with imaging. Ann Surg Oncol 2010 Mar;17(3):846-52.
13. Manassero F1, Pomara G, Rappa F, Cuttano MG, Crisci A, Selli C. Adrenal myelolipoma associated with adenoma. Int $\mathrm{J}$ Urol 2004 May;11(5):326-8.

$* * * * * * * * *$

\section{Acknowledgment}

Histopathology (Figure 2) provided courtesy of Muzaffar $\mathrm{N}$ et al: A report of three cases and review of literature. $J$ Pak Med Assoc. 2009 Jul;59(7):491-3.

\section{Author Contributions}

Chidi Okoroafor - Substantial contributions to conception and design, Acquisition of data, Analysis and interpretation of data, Drafting the article, Revising it critically for important intellectual content, Final approval of the version to be published

Catherine Obadina - Substantial contributions to conception and design, Acquisition of data, Analysis and interpretation of data, Drafting the article, Revising it critically for important intellectual content, Final approval of the version to be published

Cornelius Njoku - Substantial contributions to conception and design, Acquisition of data, Analysis and interpretation of data, Drafting the article, Revising it critically for important intellectual content, Final approval of the version to be published

Okechukwu Mgbemena - Substantial contributions to conception and design, Acquisition of data, Analysis and interpretation of data, Drafting the article, Revising it critically for important intellectual content, Final approval of the version to be published

\section{Guarantor of Submission}

The corresponding author is the guarantor of submission.

\section{Source of Support}

None.

\section{Consent Statement}

Written informed consent was obtained from the patient for publication of this case report.

\section{Conflict of Interest}

Authors declare no conflict of interest.

\section{Copyright}

(C) 2018 Chidi Okoroafor et al. This article is distributed under the terms of Creative Commons Attribution License which permits unrestricted use, distribution and reproduction in any medium provided the original author(s) and original publisher are properly credited. Please see the copyright policy on the journal website for more information. 
Access full text article on other devices

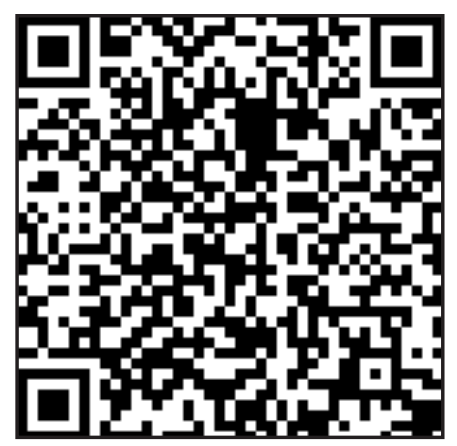

Access PDF of article on other devices

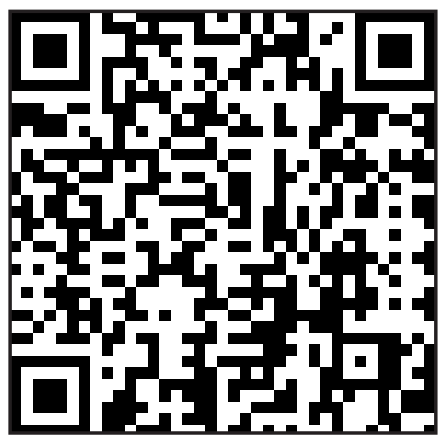

